\title{
Electrochemical Nano-Coating Processes in Solar Energy Systems
}

\author{
F. Kadırgan \\ Department of Chemistry, Istanbul Technical University, 34390 Maslak, Istanbul, Turkey
}

Received 12 February 2006; Accepted 28 April 2006

The efficiencies of electrochemically prepared nano-thick CdS and black nickel coatings were investigated as a function of their preparation conditions in the application field of energy; such as, solar-electricity conversion, solar cells, and solar-thermal conversion, spectrally selective solar collectors.

Copyright (c) 2006 F. Kadirgan. This is an open access article distributed under the Creative Commons Attribution License, which permits unrestricted use, distribution, and reproduction in any medium, provided the original work is properly cited.

\section{INTRODUCTION}

As a material becomes more and more finely divided it reaches a point whereby the physical properties that the bulk material possesses begin to differ significantly. This, of course, happens on the nano-scale. Nanocrystalline materials can be classified into different categories depending on the number of dimensions in which the material has nanometer modulations. Thus, they can be classified into (a) layered or lamellar structures, (b) filamentary structures, and (c) equiaxed nanostructured materials. A layered or lamellar structure is a one-dimensional (1D) nanostructure in which the magnitudes of length and width are much greater than the thickness that is only a few nanometers in size. Nano-structured materials vary from zero-dimensional atom clusters to threedimensional equiaxed grain structure. Each class has at least one dimension in the nanometer range. Table 1 shows this classification of the three types of nanostructures.

1D nanostructure crystallites can be prepared using electrodeposition method by utilizing the interference of one ion with the deposition of the other.

Electrodeposition yields grain sizes in the nanometer range when the electrodeposition variables (e.g., bath composition, $\mathrm{pH}$, temperature, current density, etc.) are chosen such that nucleation of new grains is favored rather than growth of existing grains [1].

This was achieved by using high-deposition rates, formation of appropriate complexes in the bath, addition of suitable surface-active elements to reduce surface diffusion of adatoms, and so forth.

Electrodeposition techniques can yield porosity-free finished products that do not require subsequent consolida- tion processing. Further, the process requires low initial capital investment and provides high-production rates with few shape and size limitations.

In this paper two electrochemically prepared nano-coating studies realized in the energy field will be given.

\section{EXPERIMENTAL}

Electrodeposited CdS films were prepared in a classical double wall, three-electrode cell under nitrogen using a $0.2 \mathrm{M}$ $\mathrm{CdCl}_{2}$ solution on indium tin oxide (ITO) coated glasses as the substrates [2]. Solutions were prepared using water purified by a Millipore-Mili-Q filtration system. ITO coated glasses were cleaned with a special detergent in an ultrasonic bat $50000 \mathrm{EUh}$ and rinsed and then ultrasonically cleaned with water. As the reference and counter electrodes, saturated calomel and glassy glass electrodes were used, respectively. The $\mathrm{pH}$ was changed from 2 up to 4 by using either HCI or $\mathrm{H}_{2} \mathrm{SO}_{4}$. The $\mathrm{Na}_{2} \mathrm{~S}_{2} \mathrm{O}_{3}$ concentration was varied between $0.01 \mathrm{M}$ and $0.05 \mathrm{M}$. All chemicals were Aldrich analytical grade. Deposition was performed applying a potential of $-0.6 \mathrm{~V} / \mathrm{SCE}$ at $80^{\circ} \mathrm{C}$ and $90^{\circ} \mathrm{C}$.

Electrochemical experiments were performed using a Voltalab impedance spectroscopy.

Jasco V 500 spectrophotometre with an integrated sphere in the UV-visible and IR ranges Kratos ES 300 electron spectrometer (Mg-K $\alpha$ or Al-K $\alpha$ X-rays) was used for the spectroscopic measurements.

The morphology and structural properties of these films were analyzed by using scanning electron microscopy (SEM) and X-ray diffraction (XRD). Surface composition of the 
TABLE 1: Classification of nanocrystalline materials.

\begin{tabular}{ccc}
\hline Dimensionality & Designation & Typical method(s) of synthesis \\
\hline One-dimensional (ID) & Layered (lamellar) & Vapor deposition \\
Two-dimensional (2D) & Filamentary & Chemical vapor deposition \\
Three-dimensional (3D) & Crystallites (equiaxed) & Gas condensation \\
& & Mechanical alloying/milling \\
\hline
\end{tabular}

films was determined by scanning Auger spectroscopy. Microscopic examination was performed to determine the pinhole and embedded particulates.

Copper has been chosen as a substrate for the preparation of spectrally selective surface [3]. Copper samples consisting of $3 \times 2 \mathrm{~cm}$ flat pieces were subjected to a chemical polishing treatment consisting of acid etchants $\left(\mathrm{H}_{3} \mathrm{PO}_{4}, \mathrm{HNO}_{3}\right.$, and $\mathrm{CH}_{3} \mathrm{COOH}$ ) at $65^{\circ} \mathrm{C}$.

\section{RESULTS AND DISCUSSION}

\subsection{Nanostructured solar cell materials}

Nanostructured layers in thin film solar cells offer three important advantages [4-6].

(i) First, due to multiple reflections, the effective optical path for absorption is much larger than the actual film thickness.

(ii) Second, light generated electrons and holes need to travel over a much shorter path and thus recombination losses are greatly reduced. As a result, the absorber layer thickness in nanostructured solar cells can be as thin as $150 \mathrm{~nm}$ instead of several micrometers in the traditional thin film solar cells.

(iii) Third, the energy band gap of various layers can be tailored to the desired design value by varying the size of nano-particles. This allows for more design flexibility in the absorber and window layers in the solar cell.

Our objective is to make a porous structure of CdS, deposit an absorber material like, copper indium diselenide, copper sulfide or cadmium telluride into the pores, and study the nanostructured $\mathrm{CdS}$ properties.

An application of nanostructured CdS to solar cells is illustrated in Figure 1.

Wider band gap makes it a more effective window layer.

CdS thin films were prepared by electrodeposition over indium tin oxide (ITO) coated glass electrodes.

Electrolyte composition, $\mathrm{pH}$ and temperature effects on the deposition time, microstructure, crystalline orientation, and surface composition of CdS films were investigated. Deposition was performed applying a potential of $-0.6 \mathrm{~V} / \mathrm{SCE}$ at $80^{\circ} \mathrm{C}$ and $90^{\circ} \mathrm{C}$.

Deposition time was chosen as comparison criteria to able to observe if the electrochemical deposition is really competitive with other preparation methods from the viewpoint of commercial application.

The surface properties of electrodeposited CdS films were compared with the films grown by other methods.

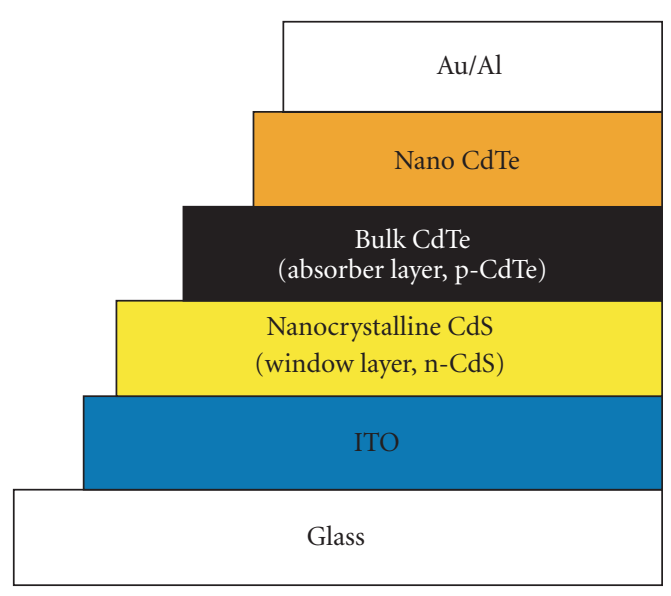

FIGURE 1: Device configuration of Glass/ITO/n-Nano-CdS/p-bulk$\mathrm{CdTe} / \mathrm{nano} \mathrm{CdTe} / \mathrm{Au} / \mathrm{Al}$ solar cell .

The resulting electrodeposited CdS thin films prepared appear uniform and smooth in terms of film quality. The reaction mechanism of $\mathrm{CdS}$ formation involves 2-electron transfer and it follows the reaction

$$
\mathrm{Cd}^{2+}+\mathrm{S}_{2} \mathrm{O}_{3}{ }^{2-}+2 \mathrm{e}^{-} \longrightarrow \mathrm{CdS}+\mathrm{SO}_{3}{ }^{2-} \text {. }
$$

Electrodeposition reaction of $\mathrm{CdS}$ is dependent on $\mathrm{pH}$, because of a disproportion reaction of the thiosulphate ions, which may occur depending on the $\mathrm{pH}$ values of the electrolyte as follows:

$$
\mathrm{S}_{2} \mathrm{O}_{3}{ }^{2-} \longrightarrow \mathrm{S}+\mathrm{SO}_{3}{ }^{2-} \text {. }
$$

Lowering the $\mathrm{pH}$ to 2 causes the decomposition of $\mathrm{S}_{2} \mathrm{O}_{3}{ }^{2-}$ and forms colloidal sulphur.

Microscopic examination was performed to determine the pinhole and embedded particulates. Before examination, the pieces were ultrasonically rinsed in methanol and dried under pressurized argon.

Pinholes and the number of surface particulates were calculated for two samples of identical thickness prepared at different conditions (see Table 2).

The sample prepared at $\mathrm{pH}=2.6$ has an order of magnitude and greater density of pinhole area than the sample prepared at $\mathrm{pH}=3$. First one has over 30 pinholes, while the second has only 9.

Optimum conditions have been obtained in $0.2 \mathrm{M} \mathrm{CdCl}_{2}$ $+0.05 \mathrm{M} \mathrm{S}_{2} \mathrm{O}_{3}{ }^{-2}$ solution at $\mathrm{pH}=3$ and $90^{\circ} \mathrm{C}$. One of the 
TABLE 2: Surface composition of CdS films prepared at pH 2.6 and 3.

\begin{tabular}{cccccc}
\hline $\mathrm{pH}$ & $\mathrm{Cd}$ & $\mathrm{S}$ & $\mathrm{O}$ & $\mathrm{C}$ & $\mathrm{Cl}$ \\
\hline 3 & 40.6 & 36.2 & 3.7 & 13.7 & 5.5 \\
2.6 & 44.4 & 29.7 & 5.5 & 11.7 & 8.4 \\
\hline
\end{tabular}

TABle 3: Properties of CdS/CdTe solar cells prepared with different CdS film thicknesses.

\begin{tabular}{ccccc}
\hline $\begin{array}{c}\text { Sample } \\
(\mathrm{CdS} \text { thickness })\end{array}$ & $\begin{array}{c}\eta \\
(\%)\end{array}$ & $\begin{array}{c}V_{\mathrm{oc}} \\
(\mathrm{mV})\end{array}$ & $\begin{array}{c}J_{\mathrm{sc}} \\
(\mathrm{mA})\end{array}$ & $\begin{array}{c}R_{\mathrm{sh}} \\
\left(\mathrm{cm}^{2}\right)\end{array}$ \\
\hline $500 \AA$ & 5.73 & 433 & 24.5 & 189 \\
$1000 \AA$ & 7.68 & 654 & 24.4 & 126 \\
$2500 \AA$ & 7.30 & 518 & 22.6 & 376 \\
\hline
\end{tabular}

aims of this work was to compare some properties of CdS films prepared by different methods such as CBD, PVD, or sputtering.

Pinhole and particulate fractional areas were very low in the case of ED CdS films. When the samples prepared by electrodeposition and CBD were compared, the crystalline phase of CBD was identified as cubic based, while the electrodeposited one was hexagonal. During the electrodeposition of $\mathrm{CdS}$ films, in the $\mathrm{Cd}^{2+}$ concentration range examined, the $\mathrm{CdS}$ deposition rate was controlled by the $\mathrm{pH}$.

Thiosulfate concentration increases the deposition rate for the $\mathrm{pH}$ values higher than 2.5. The effect of temperature was also observed on the deposition time.

Surface compositions of CdS films were prepared at two different $\mathrm{pH}$ values.

The efficiency of using electrodeposited CdS for laboratory-scale photovoltaic thin film research was demonstrated by fabrication of $\mathrm{CdTe} / \mathrm{CdS}$ devices conversion efficiencies, and ED CdS films were found to be promising for CdS/CdTe cell fabrication.

The CdS thickness was varied from $500 \AA$ to $2500 \AA$. A CdS thickness of $1000 \AA$ yielded in higher efficiency. Enhanced short-circuit photocurrent $\left(J_{\mathrm{sc}}\right)$ was caused by improved quantum efficiency in the spectral range close to the bandgap of CdS.

Cells with very thin ( $500 \AA$ ) CdS exhibit low efficiency, caused mainly by a low $V_{\text {oc }}$. An increase of CdS thickness to $2500 \AA$ lead also to a signicant decrease in $V_{\text {oc }}$ (open circuit potential), by $135 \mathrm{mV}$, resulted in a high shunt resistance $\left(R_{\mathrm{sh}}\right)$ and low efficiencies of the cells. Table 3 shows the cell properties.

Our objective was to make porous structure of CdS, deposit an absorber material like, cadmium telluride into the pores, and study the nanostructured, CdS-based heterojunction solar cells.

This structure will allow for a device design involving an $n$-type material as a porous film and an extremely thin $p$ type absorber material filling the pores.

The advantages are that the transport path for excited charge carriers in the absorber is reduced and at the same time, the optical path for photon absorption is increased.
Due to the nanoporous structure of the cell, the distance that photoexcited electrons must travel within their lifetime can be reduced to less than $100 \mathrm{~nm}$.

A CdS thickness of $1000 \AA$ yielded in higher efficiency in our work.

\subsection{Solar-thermal energy}

The effective utilization of thermal energy derived from solar radiation using either a flat plate or a focused collector system requires an efficient solar selective coating. Flat plate solar collectors have been extensively used mainly in the southern and western regions of Turkey for domestic hot water (DHW) since 1975. The absorber plates of these conventional collectors were painted with matt black paint, which had a very poor absorption/emission ratio. Furthermore, the black paint cracks and fades with time losing its characteristics and hence reducing the lifetime of the collectors. The survey on the solar collector marked indicated that there is a tremendous need for high-efficiency solar collectors to supply DHW. The development of high-efficiency solar collectors will provide more energy saving and wider applicability such as solar powered absorption refrigeration systems.

The type of coating proves significant as a criterion that determines the quality of the absorber sheet. For this coating to perform efficiently under solar radiation, its radiation properties should be as required.

An efficient coating was defined as having a high absorptance over a solar spectrum, but in addition, having a low emittance to reduce thermal radiative heat losses. The ideal values of absorptivity and emissivity are, respectively, 100\% and $0 \%$. However, in practice these values cannot be reached. Therefore, it is in the best interest to get the closest possible values to the ideal ones.

One of the most appropriate techniques for obtaining an absorber coating with selective optical properties for solar collectors is electrodeposition of metallic films [7-9].

The process provides coatings for large surfaces, it does not need complicated and expensive equipment.

Black nickel coatings have been known for good selective optical properties.

One of the disadvantages of this coating is the degradation with increasing temperature.

The reason of degradation may be explained by deposited metal-to-metal sulphides ratio. During black nickel deposition, the following two reactions are known to occur:

(i) deposition of metal sulphides,

(ii) deposition of metallic species.

The deposited metal-to-metal sulphides ratio can be controlled by the plating parameters ( $\mathrm{T}, \mathrm{pH}$, composition, current density, plating time ...). To obtain the desired solar selective surfaces, it is necessary to have both metal sulphides and free metals in the coatings.

Before the coating, commercially pure copper sheets were degreased and polished electrochemically.

Metal substrate was then coated with a layer of nickel at the first step and an outermost layer of absorbent nickel 


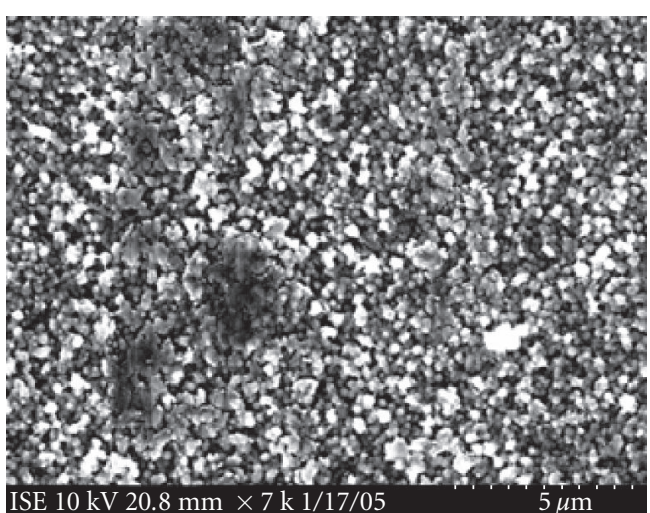

Figure 2: SEM of the first layer.

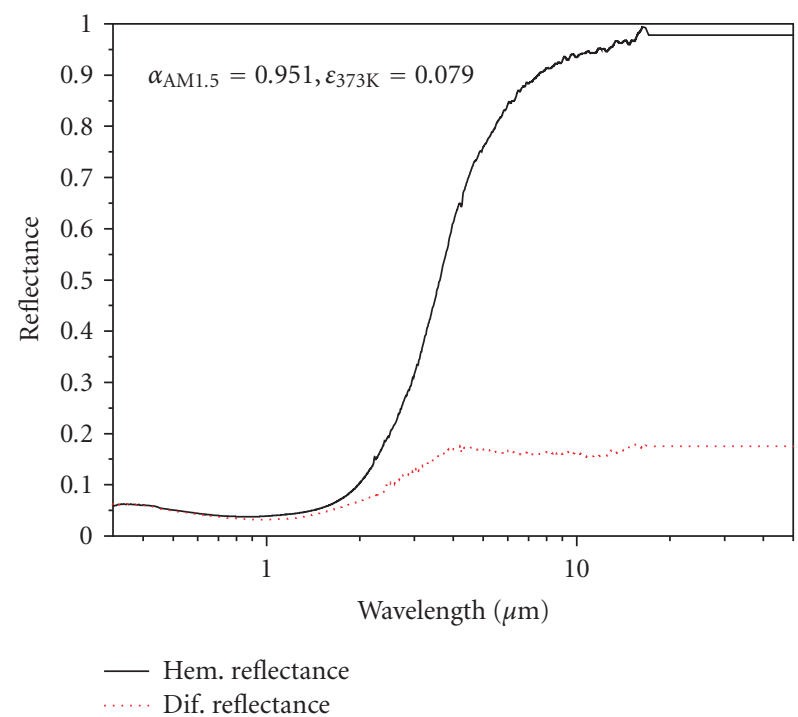

Figure 3: Spectral properties of the patented surface.

oxide-nickel zinc sulphide mixture by electrochemical deposition at relatively low temperatures at the second step. Outermost layer was a nano-thick layer $(\sim 40-70 \mathrm{~nm})$. The preparation of the surface is very important to obtain a highly efficient corrosion-resistant solar collector with a long service life and low costs. SEM pictures of the selective surface are given in Figure 2.

This coating was very stable under thermal implication and humid conditions, therefore it protects the metal surfaces against corrosion. They also presented good coverage of all the substrate and good adhesion.

Spectral properties of the patented coating [3] is given in Figure 3. Such materials have a large absorptivity in the visible and near infrared range and have little emissivity in the infrared range $(\alpha \sim 95-97, \varepsilon \sim 6-8)$ with $\alpha / \varepsilon$ ratio between 12 and 16 .

The durability tests of solar absorbers were based on the measurements of performance criteria. ISO procedure was
TABLE 4

\begin{tabular}{ccc}
\hline & As-plated & Heat-treated \\
\hline Absorption $(\alpha)$ & 97.50 & 96.46 \\
Emission $(\varepsilon)$ & 8.50 & 6.50 \\
\hline
\end{tabular}

TABLE 5

\begin{tabular}{lccc}
\hline & $\begin{array}{c}i_{\text {corr }} \\
\left(\mu \mathrm{A} \cdot \mathrm{cm}^{2}\right)\end{array}$ & $\begin{array}{c}R_{p} \\
(k \Omega)\end{array}$ & $\begin{array}{c}\text { Corrosion rate } \\
(\mu \mathrm{m} / \text { year })\end{array}$ \\
\hline Protective film & 145 & 2.74 & 170 \\
Silan coated film & 13.6 & 4.02 & 90 \\
\hline
\end{tabular}

followed for the measurements. The maximum stagnation temperature according to optical properties was determined.

The samples were kept at $200^{\circ} \mathrm{C}$ for $250-300 \mathrm{~h}$ (see Table 4).

Additional protection of the selective surface was tried using silane treatment. Nickel black films were treated with silane by a sol-gel technique. Hydrophobic silane shows a considerable inhibition capacity. The surface is obtained approximately self-cleaning upon exposure to rain, or running water, in that drops of water on the surface become substantially a sphere, and solid particles on the surface are removed from the surface together with the drops of water rolling of the surface. The sol-gel treated films keep the same $\alpha$ and $\varepsilon$ values of the nontreated films.

Corrosion behavior of the protective selective surfaces is measured by taking the cathodic and anodic polarization curves in $1 \% \mathrm{NaCl}$ solution at $80^{\circ} \mathrm{C}$. Accelerated corrosion measurements and Tafel analysis were carried out using Voltalab impedance spectroscopy. Corrosion rate, polarization resistances of protective films with and without silane coating were calculated (see Table 5).

According to the results, silane coated surfaces were more resistive towards the corrosion.

\section{CONCLUSION}

Nanocrystalline materials are novel materials that are not only scientifically interesting but also hold great potential for a number of technological applications. Their properties are different from and often superior to those of conventional coarse grained polycrystalline materials and also amorphous alloys of the same composition. Wide spread use and search for technological applications of nanocrystalline materials require the availability of large (tonnage) quantities of well-characterized materials with reproducible properties; and this needs to be done economically.

\section{REFERENCES}

[1] D. Clark, D. Wood, and U. Erb, "Industrial applications of electrodeposited nanocrystals," Nanostructured Materials, vol. 9, no. $1-8$, pp. $755-758,1997$.

[2] F. Kadirgan, D. Mao, W. Song, T. Ohno, and B. McCandless, "Properties of electrodeposited cadmium sulfide films for photovoltaic devices with comparison to CdS films prepared by 
other methods," Turkish Journal of Chemistry, vol. 24, no. 1, pp. 21-33, 2000.

[3] F. Kadırgan, Patent, PCT/TR03/00081.

[4] R. S. Singh, V. K. Rangari, S. Sanagapalli, V. Jayaraman, S. Mahendra, and V. P. Singh, "Nano-structured CdTe, CdS and $\mathrm{TiO}_{2}$ for thin film solar cell applications," Solar Energy Materials and Solar Cells, vol. 82, no. 1-2, pp. 315-330, 2004.

[5] F. Kadırgan, "Electrochemically prepared thin film solar cells," in Handbook of Advanced Electronic and Photonic Materials, H. S. Nalwa, Ed., vol. 10, chapter 6, Academic Press, New York, NY, USA, 2000

[6] V. P. Singh, R. S. Singh, G. W. Thompson, V. Jayaraman, S. Sanagapalli, and V. K. Rangari, "Characteristics of nanocrystalline CdS films fabricated by sonochemical, microwave and solution growth methods for solar cell applications," Solar Energy Materials and Solar Cells, vol. 81, no. 3, pp. 293-303, 2004.

[7] F. Kadırgan, M. Söhmen, I. E. Türe, S. Süzer, J. Wetherilt, and A. Yazar, "An investigation on the optimisation of electrochemically pigmented aluminium oxide selective collector coatings," Renewable Energy, vol. 10, no. 2-3, pp. 203-206, 1997.

[8] S. Süzer, F. Kadırgan, H. M. Söhmen, A. J. Wetherilt, and I. E. Türe, "Spectroscopic characterization of $\mathrm{Al}_{2} \mathrm{O}_{3}-\mathrm{Ni}$ selective absorbers for solar collectors," Solar Energy Materials and Solar Cells, vol. 52, no. 1-2, pp. 55-60, 1998.

[9] S. Süzer, F. Kadırgan, and H. M. Söhmen, "XPS characterization of Co and Cr pigmented copper solar absorbers," Solar Energy Materials and Solar Cells, vol. 56, no. 2, pp. 183-189, 1998. 


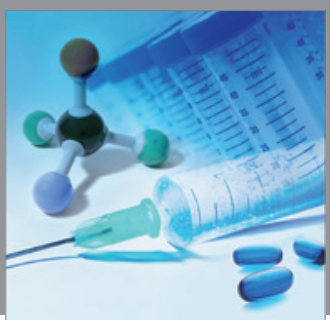

International Journal of

Medicinal Chemistry

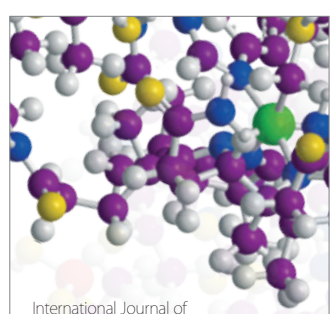

Carbohydrate Chemistry

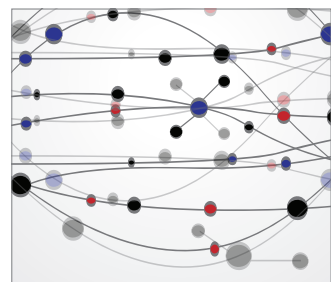

The Scientific World Journal
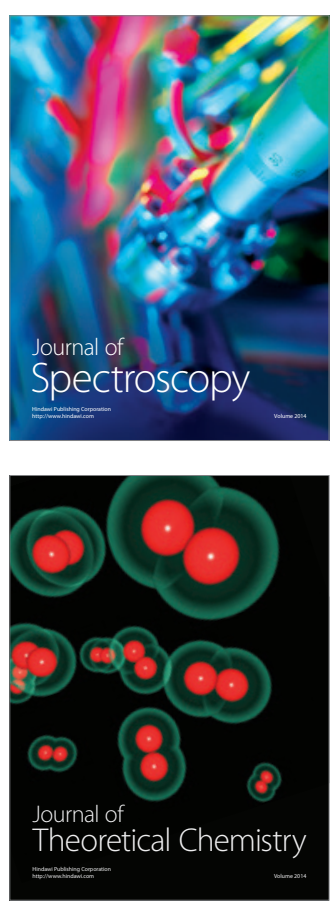
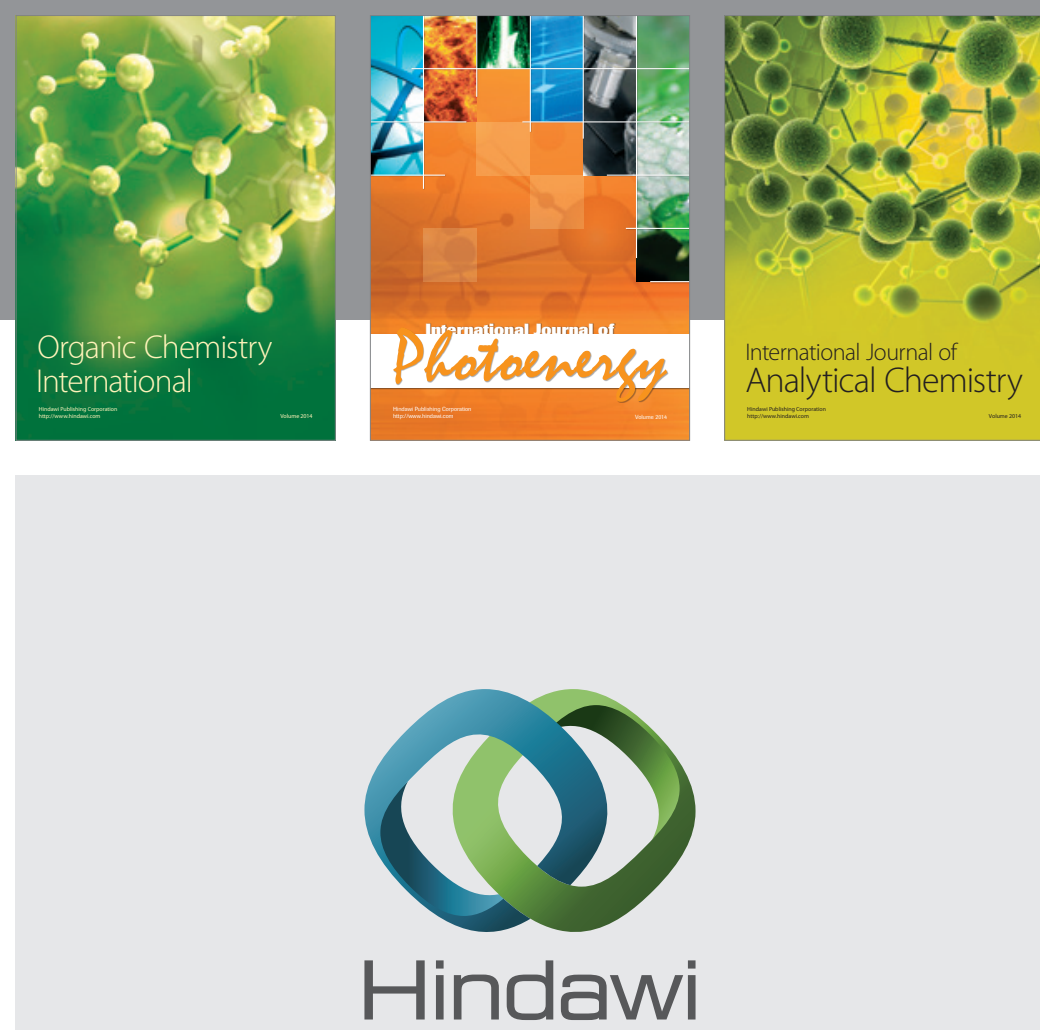

Submit your manuscripts at

http://www.hindawi.com
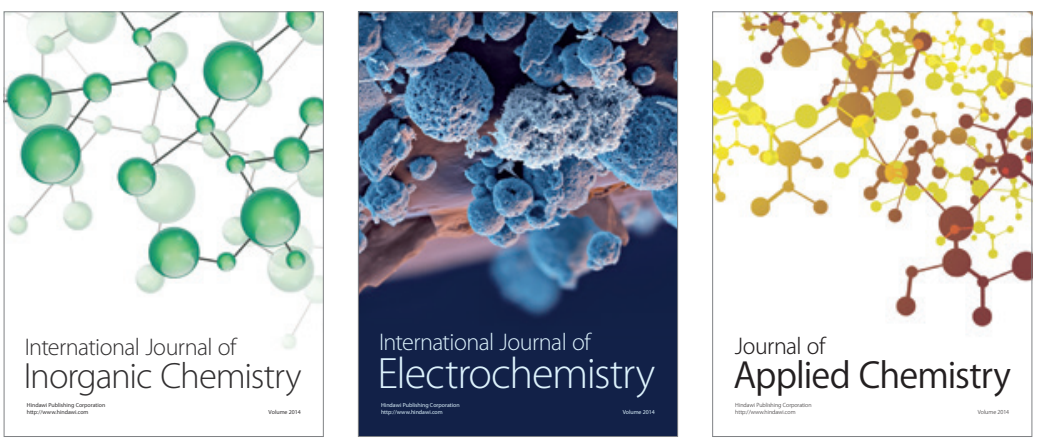

Journal of

Applied Chemistry
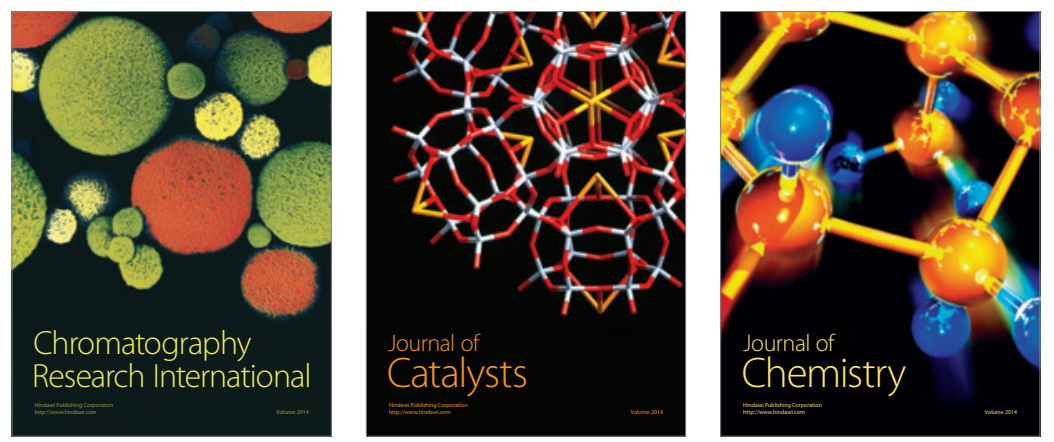
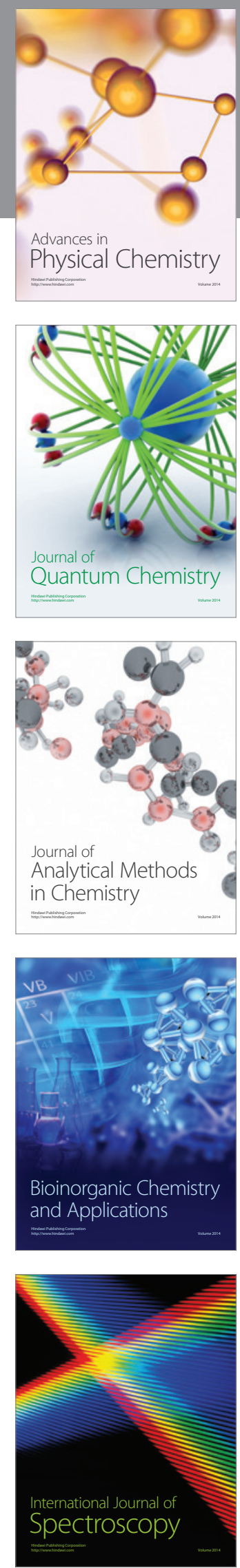